\title{
1 Sea-level responses to rapid sediment erosion and deposition in Taiwan
}

3 Gregory A. Ruetenik ${ }^{1}$, Ken L. Ferrier ${ }^{1}$, Jessica R. Creveling ${ }^{2}$, Matthew Fox $^{3}$

4

$5 \quad{ }^{1}$ Department of Geosciences, University of Wisconsin, Madison

$6 \quad{ }^{2}$ College of Earth, Ocean, and Atmospheric Sciences, Oregon State University, Corvallis, OR

$7 \quad{ }^{3}$ Department of Earth Sciences, University College London, London, UK

9 Key words: Sea level, Sediment, Taiwan, Erosion

10 Abstract

Numerous studies have shown that sediment deposition can perturb sea level by several

13 meters over millennial timescales by modifying the gravity field, crustal elevation, and sediment

14 thickness. Relatively few studies have focused on the complementary role of erosion on sea-level

15 change despite its effects on the same quantities, partly because many rapidly eroding mountains

16 are too far from shorelines to strongly perturb sea level at the coast. Taiwan, a mountainous

17 island eroding rapidly within tens of $\mathrm{km}$ of the coast, offers an opportunity to investigate the

18 joint influences of rapid onshore erosion and rapid offshore deposition on sea-level change. Here

19 we develop a sediment loading history for Taiwan since the previous interglacial ( $\sim 120 \mathrm{ka})$ by

20 compiling published erosion and deposition rate measurements and by applying a geometric

21 marine sediment deposition and compaction model for sites without deposition rate

22 measurements. We use the resulting sediment redistribution history to drive sea-level responses

23 in a gravitationally self-consistent sea-level model. Our simulations show that the effects of rapid

24 onshore erosion outweigh the effects of rapid offshore deposition along Taiwan's east coast. 
25 Along the east coast of Taiwan, sediment redistribution induces rapid sea-level fall, a response

26 that differs in sign from the coastal sea-level rise induced by rapid sediment redistribution in

27 many other river systems around the world. The spatial extent of the modeled sea-level fall is

28 sensitive to the Earth model, particularly the effective elastic thickness of the lithosphere, a

29 sensitivity that we describe in further detail in the Discussion. These results suggest that

30 sediment redistribution could have generated sea-level changes of $>10$ meters on the east coast of

31 Taiwan since $10 \mathrm{ka}$ and $>100 \mathrm{~m}$ since $120 \mathrm{ka}$. This can account for some of the discrepancy

32 between observed and modeled paleo-sea-level marker elevations, which reduces estimates of

33 tectonically driven rock uplift rates inferred from the elevation differences between paleo-sea-

34 level markers and modeled sea level. This highlights the importance of accounting for erosional

35 unloading in interpretations of paleo-sea-level reconstructions and associated estimates of

36 tectonically driven uplift rates.

\section{Introduction}

Rising sea level threatens low lying areas that contain about $10 \%$ of the world's

41 population (Nicholls and Cazenave, 2010) and motivates efforts to understand the drivers of sea-

42 level (SL) change. One of the most useful predictors of future sea-level change is the past sea-

43 level record, which can be inferred from the elevations and ages of paleoshorelines and marine

44 deposits, each of which record the cumulative sea-level change at a point in space since a given

45 time (Rovere et al., 2014). However, reconciling these local sea-level indicators with proxies for

46 global paleo-sea level, such as $\delta^{18} \mathrm{O}$ in deep-sea benthic foraminifera (Lisiecki and Raymo, 2004;

47 Doar and Kendall, 2014), is complicated by regional variations in sea level induced by 
48 viscoelastic deformation of the solid Earth in response to changes in loading of water, ice, and

49 sediment (Haskell, 1935; Milne et al., 2001; Dalca et al., 2013), crustal uplift and subsidence due

50 to tectonics and dynamic topography (Moucha et al., 2008; Rowley et al., 2013; Austermann et

51 al., 2018), and changes in Earth's gravitational field (e.g., Farrell and Clark, 1977; Tamisiea et

52 al., 2001).

53 Most studies of gravitationally self-consistent sea-level have focused on sea-level

54 responses to changes in the distribution of grounded ice (e.g., Farrell and Clark, 1977; Milne et

55 al., 2001; Mitrovica et al., 2001; Lambeck et al., 2003). Comparatively fewer studies have

56 investigated gravitationally self-consistent sea-level changes due to sediment redistribution (e.g.,

57 Dalca et al., 2013; Wolstencroft et al., 2014; Ferrier et al., 2015; Kuchar et al., 2018; Karpytchev

58 et al., 2018). Herein, we use the term "sediment redistribution" to refer to the net effects of

59 erosion and deposition of bedrock and sediment. These studies have shown that sediment

60 deposition can affect inferences of past sea level by several meters on millennial timescales (e.g.,

61 Dalca et al., 2013; Ferrier et al., 2015) and tens of meters over Myr timescales (e.g., Moucha and

62 Ruetenik, 2017) by inducing isostatic responses and modifying the gravitational field in an area

63 of up to hundreds of $\mathrm{km}$. Recently, the gravitationally self-consistent sea-level theory has been

64 extended to account for sediment compaction and sediment water storage (Ferrier et al., 2017,

65 2018).

66 On passive margins, regional changes in sea level over kyr timescales can be dominated

67 by sediment mass redistribution across the Earth's surface by erosion and deposition, which

68 deform the crust, perturb the gravity field, and shift Earth's rotation axis (e.g., Blum et al., 2008;

69 Wolstencroft et al., 2014; Ferrier et al., 2015;Moucha and Ruetenik, 2017). To date, most studies

70 of gravitationally self-consistent sea-level responses to sediment redistribution have focused on 
71 the role of rapid deposition, which in many environments is fastest near the coast, where it

72 generates crustal subsidence and local sea-level rise. Comparatively less work has evaluated the

73 sensitivity of sea-level change to rapid erosion. McGinnis et al. (1993), for example, showed that

74 erosional retreat of continental shelves during lowstands can result in tens of meters of uplift

75 over Myr timescales, which would result in overestimates of sea-level change at the Eocene-

76 Oligocene transition if not properly accounted for. Blum et al. (2008) showed that erosional

77 unloading during lowstands in the Mississippi delta region has resulted in net uplift of the land

78 surface by $>9 \mathrm{~m}$. Similarly, Ruetenik et al. (2019) showed that erosional unloading on a passive

79 margin during lowstands can result in 2-3 meters of isostatic uplift per glacial cycle. Such effects

80 may be even larger in regions where exceptionally rapid erosion occurs close to coastlines.

81 Indeed, these results suggest that if erosion close to a coastline were fast enough, the resulting

82 unloading could counteract the loading and subsidence induced by offshore deposition and result

83 in a local net sea-level fall (e.g., Woo et al., 2017). Thus, near-coastal erosion can induce a sea-

84 level response that is opposite in sign from that produced by sedimentation.

85 Here, we model sea-level responses to sediment redistribution on the rapidly eroding

86 island of Taiwan, where some of the fastest erosion rates on Earth when compared with global

87 compilation studies, e.g. Portenga and Bierman (2011) of 10+ mm/yr (Dadson et al., 2001)

88 occurs within a few tens of $\mathrm{km}$ of the modern shoreline. Our goal is to quantify sea-level

89 responses to exceptionally rapid sediment redistribution, which we illustrate using simulations

90 driven by empirically constrained estimates of erosion and deposition rates in Taiwan and its

91 surroundings. In contrast to previous studies that showed sea-level rise in response to sediment

92 redistribution (on the Mississippi, Indus, and Ganges-Brahmaputra deltas; Wolstencroft et al.,

93 2014; Ferrier et al., 2015; Simms et al., 2013; Kuchar et al., 2018; Karpytchev et al., 2018), our 
94 model results show that rapid inland erosion in Taiwan generates a large regional sea-level fall.

95 We use these modeled sea-level responses to revise estimates of tectonically driven rock uplift

96 rates along Taiwan's east coast, similar to recent revisions of tectonically driven rock uplift rates

97 along the Pacific coast of North America (Creveling et al., 2015; Simms et al., 2016).

99 2. Geologic setting: Taiwan

100

Taiwan, a product of arc-continent collision, is an island located along the Luzon arc. It

102 is bounded by the Eurasian plate on the northwest and northeast and the Philippine Sea plate to

103 the southeast $(\mathrm{Wu}, 1978)$. On the western edge of the island, the Eurasian plate subducts to the

104 east beneath the Philippine Sea plate. The Philippine Sea plate is located in the southeast and

105 subducts beneath the margin of the Eurasian plate northeast of Taiwan along the Ryuku trench

106 (Wu, 1978; Teng et al., 2000). Taiwan is thought to be an archetypical critical wedge in which

107 mass lost by erosion is balanced by shortening and accretion (e.g., Suppe, 1981). Most of the

108 island may be uplifting, but uplift rates may vary spatially (e.g. Fox et al., 2014). Overall

109 Taiwan is moving to the NW and converging against the Chinese continental margin at $\sim 80$

$110 \mathrm{~mm} / \mathrm{yr}$. However, present-day geodetic measurements show that horizontal velocities on the

111 island vary widely, particularly along the Central Valley fault which separates the Coastal Range

112 from the island's interior to the west (Yu et al., 1997). Previous studies suggested an island-wide

113 mean uplift rate of $5 \mathrm{~mm} / \mathrm{yr}$ (Suppe, 1989), while more recently it has been suggested that long-

114 term uplift rates may be highest in the north central part of the island, and lower in the south

115 (e.g., Fox et al., 2014). Modern geodetic measurements suggest that the southern Coastal Range 
116 may be uplifting at rates ranging from $0 \mathrm{~mm} / \mathrm{yr}$ on the eastern margin to $>10 \mathrm{~mm} / \mathrm{yr}$ in the

117 western margin (Hsu et al., 2018).

118 Crustal thickness may be $40 \mathrm{~km}$ or higher (Szwillis et al., 2016). Rapid uplift has

119 produced high topography $(>3 \mathrm{~km})$ in the Central Range that is thought to have begun around 4

$120 \mathrm{Ma}$ (Suppe, 1981). Along the central eastern shore, the $\sim 1.5 \mathrm{~km}$ high Coastal Range is thought to

121 have uplifted more recently (e.g., Fox et al., 2014; Hsu et al., 2016).

122 Due to its wet, monsoonal climate and rapid rock uplift rates, Taiwan experiences some

123 of the fastest exhumation and erosion rates on the planet (e.g., Portenga and Bierman, 2011;

124 Milliman and Farnsworth, 2011). Myr-scale exhumation rates reach 6-10 mm/yr (Liu et al.,

125 2001; Willett et al., 2003) and modern decadal-scale, basin-averaged erosion rates are as high as

$126 \sim 12 \mathrm{~mm} / \mathrm{yr}$ have been reported (Dadson et al., 2003). Offshore postglacial deposition rates

127 exceed $10 \mathrm{~mm} / \mathrm{yr}$ in the Taiwan Strait (Liu et al., 2008). Ongoing, rapid uplift of the eastern

128 Coastal Range has uplifted and exposed a series of marine deposits along Taiwan's east coast

129 that formed during the last $15 \mathrm{ka}$ (e.g., Hsieh et al., 2004; Figure 1). The close proximity $(<20$

$130 \mathrm{~km}$ ) of these rapid erosion and deposition rates to dated SL markers make Taiwan an ideal

131 setting to investigate the joint influence of erosion and deposition on sea-level change.

\section{3. Methods}

1353.1 Model overview

To explore the influence of rapid erosion and deposition on modeled sea-level change, we

138 adopt the methodology of Ferrier et al. (2017), which extended the gravitationally self-consistent 
139 sea-level theory of Dalca et al. (2013) by accounting for sediment compaction and sedimentary

140 water storage. Here we give a brief overview of the model and refer the reader to these

141 references for a full description of the model.

$142 \quad$ Following Farrell and Clark (1976), we compute the change in sea level from one time to 143 another $(\triangle S L)$ as the elevation difference between the sea surface and the solid surface (Equation

144 1). $\Delta H$ and $\Delta I$ are changes in the thicknesses of sediment and grounded ice, respectively, and $\Delta G$ 145 and $\Delta R$ are the resulting changes in the elevations of the sea-surface gravitational equipotential 146 and bedrock, respectively. In Equation 1, each of these terms is implicitly a function of time and 147 space.

$$
\Delta S L=\Delta G-\Delta H-\Delta I-\Delta R
$$

Here, $\Delta H$ and $\Delta I$ are imposed a priori and used to drive the model, while $\Delta G$ and $\Delta R$ are 152 computed as responses to $\Delta H$ and $\Delta I$ (Dalca et al., 2013; Ferrier et al., 2017). As in most 153 implementations of the gravitationally self-consistent sea-level theory, we compute $\Delta G$ and $\Delta R$ 154 using a spherically symmetric Earth model (Kendall et al., 2005; de Boer et al., 2017) following 155 viscoelastic Love number theory (Peltier, 1974; Dalca et al., 2013). These are computed up to 156 spherical harmonic degree and order 1024. The Earth model we adopt is characterized by a 157 viscoelastic mantle with radially varying elasticity and density profiles taken from PREM 158 (Dziewonski and Anderson, 1981), viscosities of the upper and lower mantle of $5 \times 10^{20} \mathrm{~Pa}$ s and $1595 \times 10^{21} \mathrm{~Pa} \mathrm{~s}$, respectively (e.g., Austermann et al., 2015), and an effective elastic lithospheric 160 thickness $\left(T_{e}\right)$. To illustrate the influence of $T_{e}$ on modeled sea-level responses, we present 161 results from two simulations with identical mantle properties but different $T_{e}$ values. In the first, 
162 SL10, we set $T_{e}=10 \mathrm{~km}$, consistent with estimates for southwestern Taiwan (e.g., Lin and

163 Watts., 2002). In the second, SL30, we set $T_{e}=30 \mathrm{~km}$, consistent with estimates for central

164 Taiwan (Chen et al., 2013). We apply this range of $T_{e}$ values because they are consistent with

165 regional estimates of the effective elastic lithospheric thickness, unlike the higher $\mathrm{T}_{\mathrm{e}}$ value in the

166 VM2 Earth model, which was used in the inversion for the ICE-5G ice history (Peltier, 2004).

167 Applying an artificially large $T_{e}$ value would produce an artificially long-wavelength response to

168 the sediment redistribution history in Taiwan, which would mask the spatial variations in

169 sedimentary effects on sea-level change that are the central focus of this study.

170 In all simulations, we apply a history of ice mass variations $\Delta I$ given by ICE-5G (Peltier,

171 2004), extended from the Last Glacial Maximum to the Last Interglacial (122 ka) following

172 Raymo et al. (2011).

173

\section{$174 \quad 3.2$ Sediment redistribution history}

175

The quantities required to model sea-level responses to sediment redistribution are mean

177 sediment porosity $\bar{\phi}$, mean sediment density $\bar{\rho}_{H}$, and the change in sediment thickness $\Delta H$

178 (Ferrier et al., 2017) These require knowledge of the rates and patterns of erosion and deposition 179 across the study region throughout the time period of interest.

180 We constructed maps of erosion and deposition rates to drive model sea-level responses

181 (Figure 2). To construct the history of erosion on land, we applied the average erosion rates for

182 Taiwan over the past $\sim 80 \mathrm{ka}$ inferred from inverse stream profile modeling (Fox et al., 2014). In

183 our simulations these rates vary in space and are constant in time as the 120-kyr duration of our

184 simulations is similar to the $\sim 80$-kyr timestep used by Fox et al. (2014). Erosion rates are highest 
185 in the Central Range, reaching up to $12 \mathrm{~mm} / \mathrm{yr}$, and gradually drop to nearly $0 \mathrm{~mm} / \mathrm{yr}$ near the 186 Western Foothills near the coastal plain. Our sediment redistribution history is characterized by 187 sediment deposition that is thickest on the eastern margin where there is greater accommodation, 188 while sedimentary deposits are thinner and more widely dispersed along the shallow western 189 margin. Modeled deposition rates and patterns evolve over time, such that during highstands 190 deposition is concentrated near the shore on the shallow west coast, while during lowstands, 191 depocenters on the west coast move outboard. On the east coast deposited sediment slowly 192 progrades outboard but the depocenter locations and deposition rates remain relatively constant 193 in space and time.

194 To reconstruct the history of deposition, we adopted published measurements of

195 Holocene deposition rates on Taiwan's western coastal plain and the Taiwan Strait, inferred from 196 measurements of post-glacial sediment thickness (Liu et al., 2008). In the absence of 197 measurements of higher-frequency deposition rate variations, we apply these as temporally 198 steady deposition rates from $12 \mathrm{ka}$ to the present in these regions. As far as we are aware, there 199 are few empirical constraints on deposition rates for periods further in the past and at other 200 locations offshore around Taiwan. For these periods and regions, we use the fluvial land-to201 ocean sediment fluxes determined from upstream integration of erosion by Fox et al. (2014) to 202 drive a geometric sediment deposition model (Reynolds et al., 1991; Ruetenik et al., 2016), 203 which computes the growth of sedimentary deposits at the outlets of Taiwan's major rivers. In 204 this model, sediment transport from source (land) to sink (nearest ocean outlet) is assumed to be 205 instantaneous. This deposition model distributes sediment in a conical shape, such that if the 206 sediment source (river outlet) remained stationary over time, the plan view morphology of the 207 deposit would be shaped like a wedge of a circle, with a point at the river outlet, two straight 
208 sides emanating seaward from that point, and an arc segment connecting the sides. In profile, the 209 deposit slopes downward at a constant "cone angle" from the high point at the river outlet to the 210 ocean floor. If the model sedimentary deposit fills up (aggrades) to sea level, then the deposit 211 progrades at a constant "subaerial angle". We take the cone angle to be $1^{\circ}$, consistent with the

212 present-day angle of the continental slope on the southern edge of Taiwan (further away from the

213 Ryuku trench), and $0.02^{\circ}$ for the "subaerial angle", consistent with the shelf slope on the western

214 margin. In this construction, the location of the cone's source point varies over time as the

215 shoreline migrates, which we compute in a sea-level simulation driven by ice mass variations at

216 1-kyr timesteps. The deposition model adopts a DEM with present-day bathymetry at $\sim 900 \mathrm{~m}$

217 resolution (SRTM30+, Becker et al., 2007), and modeled deposition patterns evolve according to 218 the spatial variations in bathymetry throughout the model run.

219 Because the modeled deposits are fed by the eroded mass fluxes from 122 to 12 ka, over

220 this time period the integrated eroded mass over the model domain equals the integrated

221 deposited mass. From 12 ka to the present, modeled deposition rates in the Taiwan Strait

222 increase from zero (Figure 2b) to the values adopted from Liu et al. (2008) (Figure 2c), which

223 results in an integrated deposition rate that is $\sim 1.4$ times higher than the integrated erosion rate

224 during this time. The temporal evolution of bathymetry is part of the reason why sediment

225 deposition patterns are different in the previous highstand (Figure 2a) relative to those in the 226 present highstand (Figure 2c).

227 Since this $12-\mathrm{kyr}$ duration is $\sim 10 \%$ of the $122-\mathrm{kyr}$ simulation, over the duration of the 228 simulation the cumulative deposited mass is $\sim 4 \%$ higher than the cumulative eroded mass.

229 For depositional areas, we follow Ferrier et al. $(2017,2018)$ in computing the rate of 230 change of sediment thickness as the difference between the rates of deposition and compaction, 
231 with sediment deposited at an initial porosity of 0.6 and compacting at a rate given by Equation 2322.

$$
\frac{d \phi(z)}{d t}=-k \sigma_{d}(z)\left(\phi(z)-\phi_{\min }\right)
$$

235 Here $\phi(z)$ is the porosity at depth $z$ below the sediment surface, $\phi_{\min }$ is the minimum porosity in

236 fully compacted sediment, $k$ is a compaction coefficient, and $\sigma_{d}(z)$ is the difference between

237 lithostatic and hydrostatic stress at depth $z$, which depends on the sediment grain density $\rho_{s}$ and

238 water density $\rho_{w}$. Following Ferrier et al. $(2017,2018)$, we adopt values of $\rho_{s}=2700 \mathrm{~kg} \mathrm{~m}^{-3}$,

$239 \rho_{w}=1000 \mathrm{~kg} \mathrm{~m}^{-3}, \phi_{\min }=0.2$, and $k=10^{-17} \mathrm{~Pa}^{-1} \mathrm{~s}^{-1}$. This approach yields vertical profiles of

240 sediment density and porosity that vary over time, which we use to compute time series of mean

241 sediment column density $\bar{\rho}_{H}$, mean sediment column porosity $\bar{\phi}$, and sediment thickness $\Delta H$

242 throughout the depositional region. These are the sedimentary inputs with which we drive the 243 sea-level simulations.

\section{Results}

We used the model in Section 3 to compute sea-level changes over the last glacial cycle

248 (122 ka) in two simulations, one driven by sediment redistribution and global ice volume change, 249 and the other driven only by global ice volume change (Figure 3). In each simulation, the Earth 250 model has the same effective elastic lithospheric thickness $T_{e}=30 \mathrm{~km}$, consistent with estimates

251 for central Taiwan (Chen et al., 2013). The difference between these simulations is shown in the

252 right-hand column in Figure 3, which reveals the net effect of sediment redistribution on sea253 level change. 
The combination of the responses in crustal elevation and sea-surface equipotential yield

255 the response in sea level. Figure 3a shows the sea-level response as $\Delta \mathrm{SL}_{\mathrm{GR}}=\Delta \mathrm{G}-\Delta \mathrm{R}$, which is

256 the relevant quantity to compare to sea-level changes inferred from paleo-sea-level markers,

257 since such markers have avoided direct changes in ice thickness and sediment thickness and,

258 thus, locally have $\Delta \mathrm{I}=0 \mathrm{~m}$ and $\Delta \mathrm{H}=0 \mathrm{~m}$ in Equation 1 (e.g., Ferrier et al., 2017). Here, the

259 pattern of high $\Delta S L_{G R}$ is dominated by the response in $\Delta R$, as is common in responses to

260 sediment redistribution (e.g., Dalca et al., 2013; Wolstencroft et al., 2014; Ferrier et al., 2015).

The dominant response to erosion is a dome-like pattern of rock uplift (i.e., positive $\Delta R$ )

263 which reaches a maximum amplitude of $170 \mathrm{~m}$ in central Taiwan (Figure 3b). This response in

$264 \Delta R$ has a wavelength of $\sim 300-500 \mathrm{~km}$, dropping off to $5 \%$ of its maximum amplitude at distances

265 of $\sim 150-250 \mathrm{~km}$ from the dome center. By comparison, the response of the sea-surface

266 equipotential, $\Delta G$, to sediment redistribution is smaller, with a maximum amplitude of $6 \mathrm{~m}$

267 (Figure 3c).

To illustrate the sensitivity of the modeled responses to the effective elastic thickness, we

269 conducted a second simulation with the same ice and sediment redistribution histories as in

270 Figure 3, but with a lithospheric effective elastic thickness of $10 \mathrm{~km}$ instead of $30 \mathrm{~km}$. A

271 comparison of these results show that the adopted effective elastic thickness affects both the

272 wavelength and amplitude of the modeled sea-level responses (Figure 4). The maximum

273 amplitude of the sea-level response is larger in the simulation with the less rigid lithosphere

274 (SL10), reaching $370 \mathrm{~m}$ (compared with $170 \mathrm{~m}$ in the simulation with the more rigid lithosphere,

275 SL30). These sea-level responses are large mainly because the subaerial eroded thickness is

276 large, totaling $>600 \mathrm{~m}$ in the most rapidly eroding areas over the $122-\mathrm{kyr}$ simulation. In contrast, 
277 the lateral extent of the response, which we operationally define as the distance from the location

278 of maximum $\Delta S L$ to the nearest point where $\Delta S L$ drops to $5 \%$ of the maximum response, is larger

279 in the simulation with more rigid lithosphere, approximately $65 \mathrm{~km}$ in SL10 and $145 \mathrm{~km}$ in

$280 \quad$ SL30.

281

282 5. Discussion

283

284

5.1 Patterns and drivers of modeled sea-level change

285

Figure 4 shows that modeled sea-level responses to sediment redistribution form a bullseye pattern around Taiwan with a radius that depends on the lithosphere's effective elastic thickness. Along Taiwan's east coast, sediment loading over the 122-kyr simulation induced a sea-level fall of 120-138 $\mathrm{m}$ in the 30-km $T_{e}$ simulation and $113-180 \mathrm{~m}$ in the 10-km $T_{e}$

290 simulation (Figure 4). This largely reflects crustal uplift $(\Delta R)$ in response to erosional unloading

291 on land since the crustal response is much larger than the gravitational response ( $\Delta G$; Figure 3),

292 consistent with previous studies (e.g., Dalca et al., 2013). This behavior, in which sediment

293 redistribution drives sea-level fall rather than sea-level rise, is unusual relative to many coastal

294 sites with large sediment fluxes elsewhere around the world. In many large river systems, the 295 area on both sides of the coast is dominated by sediment deposition, both in marine deposits 296 offshore and in low-gradient floodplains on land (e.g., the Mississippi, Indus, and Yellow River 297 deltas; Wolstencroft et al., 2014; Ferrier et al., 2015; Pico et al., 2016; Kuchar et al., 2018). In 298 such areas, the combination of subaerial and submarine deposition induces a broad region of 299 crustal subsidence both onshore and offshore, which in turn drives sea-level rise along the coast. 
Meanwhile, the eastern side of Taiwan is characterized by rapid erosion on land and rapid

301 deposition offshore (Figure 2). As Figure 3a shows, the crustal uplift induced by erosion more

302 than offsets the subsidence induced by deposition offshore, such that the coast experiences net

303 uplift and hence sea-level fall. This is due in part to the fact that the change in the total load is

304 larger for a given mass of subaerial eroded sediment than for the same mass of submarine

305 deposited sediment. The space occupied by newly deposited marine sediment had formerly been

306 occupied by water, whereas the space evacuated by eroded subaerial sediment is replaced by air.

307 The magnitude of the total mass load change is therefore greater for a given mass of eroded

308 sediment than for the same mass of deposited marine sediment. The magnitude of the sea-level

309 fall is large relative to estimates of changes in global mean sea level from the Last Interglacial to

310 the present (6-9 m; Kopp et al., 2009; Dutton and Lambeck, 2012). This illustrates that erosion

311 near coasts can strongly affect both the magnitude and the sign of present-day paleoshoreline and

312 SL marker elevations.

\subsection{Comparison of modeled sea-level changes to observed sea-level changes}

316 In many coastal regions around the world, the most prominent SL markers and

317 paleoshorelines are those that formed during the Last Interglacial (LIG). These are often well

318 preserved because the combined effects of eustatic, crustal, and gravitational changes since the

319 LIG tend to leave them a relatively short vertical distance above the modern sea surface and

320 relatively free of erosional modification (e.g., Merritts and Bull, 1989; Dutton and Lambeck,

321 2012; Creveling et al., 2015, 2017). In eastern Taiwan, however, our simulations suggest that

322 LIG SL markers should lie at much higher elevations, with sediment redistribution alone 
323 generating $80-150 \mathrm{~m}$ of rock uplift relative to the modern sea surface. More problematically for

324 sea-level reconstructions, the same intense erosional processes that induce rapid uplift of

325 Taiwan's sea-level markers also induce their rapid destruction. As a result, no preserved LIG

326 sea-level markers are reported from eastern Taiwan, as far as we are aware. Instead, the oldest

327 known sea-level markers in this region are no older than $\sim 15 \mathrm{ka}$ (Hsieh et al, 2004). Thus, our

328 ability to compare modeled sea-level changes to observed sea-level changes in Taiwan stretches

329 back no further than the past $15 \mathrm{kyr}$.

330 RSL markers vary by type, from fossils to anthropogenic artifacts, and each type has an

331 associated, and often broad, indicative range of paleo water depth (Rovere et al., 2016). The

332 RSL data presented in Hsieh et al. (2004) contains a range of well-constrained sea-level markers

333 (deposited within one meter of sea level), as well as markers which have an unconstrained range

334 of deposition. These consist of fossil wood, peat, shells, algae, and corals. As in Hsieh et al.

335 (2004), we assume that tectonic uplift rates based on the unconstrained RSL markers are minima.

336 For a rigorous discussion of RSL marker depth uncertainty we refer the interested reader to

337 Hsieh et al. (2004). Here we adopt these bounds in assessing the influence of sediment

338 redistribution on inferred tectonic uplift rate.

339 In Figure 5, local sea-level histories inferred from dated sea-level markers are shown as

340 gray boxes and triangles, the sizes of which indicate uncertainties in SL marker elevation and age

341 (Hsieh et al., 2004). Triangles represent unconstrained deposits that provide only a lower bound

342 on elevation. Since the $\sim 4-15$ ka ages of these paleo-sea-level markers are much older than the

$343 \sim 10^{2}$-year duration of the earthquake cycle (Chen, 2003), they reflect the cumulative change in

344 sea level due to the combination of tectonic deformation (coseismic inelastic strain and

345 interseismic elastic strain) and the responses to sediment redistribution and ice mass changes. 
Superimposed on the data are modeled relative sea level histories, $R S L(t)$, that represent

347 the difference between sea level at a past time $t$ and the present time $t_{p}$. This is defined as $R S L(t)$

$348=S L_{G R}(t)-S L_{G R}\left(t_{p}\right)$, which is equivalent to $-\Delta S L_{G R}$ from $t$ to $t_{p}$ (e.g., Ferrier et al., 2015). Four

349 modeled sea-level histories are shown in Figure 5, each representing a different combination of

350 loading histories and Earth model. The vertical width of each colored region represents the

351 spatial variability in $R S L(t)$ responses along Taiwan's east coast.

352 Figure 5 shows that the observed SL markers on Taiwan's east coast sit at higher

353 elevations than the modeled correlative paleo-sea-levels in all simulations. We interpret the

354 differences between modeled and measured elevations as a reflection of tectonically driven rock

355 uplift which are generally smaller in simulations that include the effects of sediment

356 redistribution. Therefore, we suggest that sediment redistribution plays a significant role in

357 explaining the present elevation of Taiwan's sea-level markers. Specifically, the effects of

358 sediment redistribution account for $16-100 \%$ of the estimated difference between observed and

359 modeled sea-level marker elevations over the past $10 \mathrm{ka}$. This implies that sea-level simulations

360 that include sediment redistribution can be used to refine estimates of tectonically driven rock

361 uplift rates inferred from SL markers in Taiwan (see section 5.3).

362 Our simulations also show that sediment redistribution may have induced significant

363 perturbations in sea level tens of km east of Taiwan. In Figure 6, solid and dashed lines show

364 modeled sea-level changes on the islands of Lutao and Lanyu, $\sim 30-65 \mathrm{~km}$ from Taiwan's east

365 coast (Figure 1; Vita-Finzi, 2000; Wang and Burnett (1990)). At each of these sites, the role of

366 sediment redistribution in $R S L$ change is small relative to those in eastern Taiwan. On Lutao and

367 Lanyu, however, the responses are large enough to be significant relative to the elevation of SL

368 markers there. For example, sediment redistribution perturbs modeled $R S L$ estimates in Lutao by 
up to 4 meters at $6 \mathrm{ka}$, which is greater than the 1-3 m elevation of the 4-6 ka correlative SL marker elevation there (Vita-Finzi, 2000; Wang and Burnett (1990)).

All sea-level markers are subject to uncertainty in age and depth of deposition. The depth

372 of deposition reported in Hsieh et al. (2004) ranges from -1 to 1 meters for some markers

373 (negative values indicating deposition on land by tidal processes) and upwards of 10 meters for

374 others (Supplementary Table 1). For other data sets, depth ranges were not reported (Wang and

375 Burnett, 1990; Vita-Finzi, 2000), in part because the species of corals were not reported for some

376 markers, and corals can range in depth from 3 to $20 \mathrm{~m}$ (Wang and Burnett, 1990). We therefore

377 consider estimates of rock uplift based on these sea-level markers to be lower bounds.

5.3 Influence of sediment redistribution on inferences of tectonically driven uplift

The influence of sediment redistribution on sea level has important implications for

382 efforts to use paleo-sea-level changes to infer tectonically driven rock uplift rates. These are

383 often determined by rewriting Equation 1 as $\Delta R=\Delta G-\Delta S L=\Delta G+R S L$ (e.g., Muhs et al.,

384 1990; Creveling et al., 2015; Simms et al., 2015) and attributing $\Delta R$ to tectonically driven rock

385 uplift. In practice, $R S L$ is often determined from the elevations and ages of paleo-sea-level

386 markers, while $\Delta G$ is often determined from simulations of sea-level change driven by global ice

387 changes. Tectonically driven rock uplift rates are then calculated as $U_{\text {tectonic }}=\Delta R / \Delta t$, where $\Delta t$ is

388 the age of the paleo-sea-level marker.

In places like Taiwan that experience significant sediment redistribution, a portion of $\Delta R$

390 is generated by isostatic responses to surface loads. Therefore, only a fraction of $\Delta R$ is

391 attributable to tectonically driven rock uplift. In such places, we may write $\Delta R \approx \Delta R_{\text {sediment }}+$ 
$392 \Delta R_{\text {tectonic, }}$, where $\Delta R_{\text {sediment }}$ is the sediment-driven change in crustal elevation and $\Delta R_{\text {tectonic }}$ is the

393 residual change in crustal elevation by tectonically driven rock uplift. This approximation is

394 appropriate to the extent that other contributions to vertical crustal motion (e.g., by dynamic

395 topography) are small relative to those driven by sediment and tectonics. A global simulation of

396 sea-level responses to dynamic topography suggest a rate of sea-level change of $0.04 \mathrm{~mm} / \mathrm{yr}$

397 driven by dynamic topography off Taiwan's east coast over the past glacial cycle (Austermann et

398 al., 2017), which is $<1 \%$ of the maximum rates of vertical motion inferred for our study sites in

399 Taiwan (Figure 6). We therefore suggest that contributions to $\Delta R$ from dynamic topography are

400 likely to be small relative to the contributions from sediment and tectonics in Taiwan, and that

$401 \Delta R \approx \Delta R_{\text {sediment }}+\Delta R_{\text {tectonic }}$ is a reasonable approximation for our study sites. Under this

402 approximation, revised estimates of tectonically driven rock uplift rates can be calculated as

$U_{\text {tectonic }}=\Delta R_{\text {tectonic }} / \Delta t=\left(\Delta R-\Delta R_{\text {sediment }}\right) / \Delta t$.

404 We calculate $\Delta R_{\text {tectonic }}$ as the difference between observed $R S L$ and modeled $R S L$, where

405 the former is determined from SL marker elevations (which yield $\Delta R$ ), and the latter is

406 determined from simulations driven by regional sediment redistribution and global ice changes

407 (which yield $\Delta R_{\text {sediment }}$; e.g., Figure 3a). The observations and simulations are summarized in

408 Figure 5, which shows observed SL marker ages and elevations along Taiwan's east coast (black

409 boxes and triangles) as well as modeled $R S L$ histories in the same region in simulations driven by

410 sediment and ice variations or only by ice variations.

411 Figure 5 reveals that sediment redistribution in Taiwan has significant effects on modeled

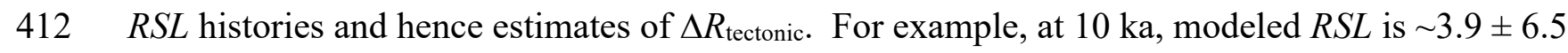

$413 \mathrm{~m}$ in simulations that include sediment redistribution and $-10.9 \pm 1.4 \mathrm{~m}$ in simulations that

414 neglect it. Thus, accounting for sediment redistribution can reduce estimates of $\Delta R_{\text {tectonic }}$ by 
$415 \sim 14.8 \pm 6.6 \mathrm{~m}$ at $10 \mathrm{ka}$ along Taiwan's east coast. For the lower-altitude SL markers at $10 \mathrm{ka}$,

416 which presently have an elevation of $\sim 14 \mathrm{~m}$, this reduces estimates of $\Delta R_{\text {tectonic }}$ by more than a

417 factor of 2 , from $24.9 \pm 1.4 \mathrm{~m}(14 \mathrm{~m}-(-10.9 \pm 1.4 \mathrm{~m}))$ to $10.1 \pm 6.5 \mathrm{~m}(14 \mathrm{~m}-(3.9 \pm 6.5 \mathrm{~m}))$

418 (Figure 5).

419 We use these revised estimates of $\Delta R_{\text {tectonic }}$ to calculate new estimates of tectonically

420 driven rock uplift rates. At each area along Taiwan's east coast (correlative regions as defined

421 by Hsieh et al., 2004), we calculate $U_{\text {tectonic }}$ (Figure 7a) as the slope of a linear regression between

$422 \Delta R_{\text {tectonic }}$ and SL marker age forced through the origin (Figure $7 \mathrm{~b}$ ), since both observed and

423 modeled $R S L$ must be zero at present. To demonstrate the effects of sediment redistribution on

424 estimates of $U_{\text {tectonic, }}$ we calculate what the inferred tectonically driven rock uplift rates would

425 have been if sediment redistribution were neglected. We term this $U_{\text {tectonic, ice-only, and we }}$

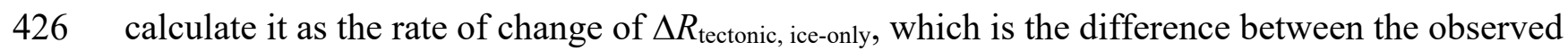

$427 R S L$ and modeled $R S L$ in a simulation driven only by ice changes (Figure $3 \mathrm{~d}$ ). As with $U_{\text {tectonic, }}$

428 we calculate $U_{\text {tectonic, ice-only }}$ as the slope of a linear regression between $\Delta R_{\text {tectonic, ice-only }}$ and SL

429 marker age.

$430 \quad$ Figure 7 shows these revised estimates of $U_{\text {tectonic, }}$, which reveal that sediment

431 redistribution can have a significant effect on estimates of tectonically driven rock uplift rates.

432 Estimates of $U_{\text {tectonic }}$ are $\sim 1-2 \mathrm{~mm} \mathrm{yr}^{-1}$ lower than $U_{\text {tectonic, ice-only, which vary with latitude from } \sim 0}$

433 to $6 \mathrm{~mm} \mathrm{yr}^{-1}$. This implies that estimates of tectonically driven uplift rates inferred from SL

434 markers along Taiwan's coast would be significantly reduced by accounting for the effects of

435 sediment redistribution on sea-level change. The patterns of uplift remain unchanged, with uplift

436 rates generally tapering off near the inferred fault at $23^{\circ} \mathrm{N}$ (e.g., Vita-Finzi and Lin, 1998; Figure

437 7). 
Lastly, our revised estimates of $U_{\text {tectonic }}$ show that accounting for sediment redistribution can help refine the magnitude of inferred rock uplift rates across spatial discontinuities in rock

440 uplift rate. In Figure 7a, inferred rock uplift rates reach a minimum of about $-1.5 \mathrm{~mm} / \mathrm{yr}$ in the $T_{e}$

$441=30 \mathrm{~km}$ Earth model at $\sim 23^{\circ} \mathrm{N}$, which is the location of a proposed fault (Vita-Finzi and Lin,

442 1998). These rates increase to near their maximum rates just south of this fault, and gradually

443 increase to the north to $\sim 5 \mathrm{~mm} / \mathrm{yr}$ before decreasing again around $23.3^{\circ} \mathrm{N}$. Around $23.5^{\circ} \mathrm{N}$ rates

444 reach a local minimum of at least $\sim 0 \mathrm{~mm} / \mathrm{yr}$ before increasing again to a local maximum of $\sim 5$

$445 \mathrm{~mm} / \mathrm{yr}$ at $23.7^{\circ} \mathrm{N}$. This discontinuity in rock uplift rate is apparent in simulations driven by ice

446 and sediment, as well as in simulations driven only by ice mass variations. These short-

447 wavelength (tens of $\mathrm{km}$ ) variations are unlikely to be driven by sediment redistribution, which in

448 these simulations drives sea-level changes that vary smoothly over wavelengths $>100 \mathrm{~km}$ (Figure

449 3). Our revised rock uplift rates are therefore consistent with the interpreted location of the

450 proposed fault.

\subsection{Sensitivity to sediment redistribution history and Earth model}

455 factors, including the reconstructed sediment redistribution history, the adopted Earth model, 456 and, to a lesser extent in our study area, the adopted global ice history. Uncertainties associated 457 with the ice history are comparatively small because the $\Delta S L$ response to $\Delta I$ in Taiwan is much 458 smaller than the response to $\Delta H$ (e.g., compare Figures $3 \mathrm{a}$ and $3 \mathrm{~d}$ ). This is a consequence of the $459>8000-\mathrm{km}$ distance between Taiwan and the Antarctic, Laurentide and Fennoscandian ice sheets, 
460 which were the main locations of ice mass variations over the last glacial cycle. Thus, here we

461 focus on the uncertainties in the sediment redistribution history and the Earth model.

462 Our reconstruction of the sediment redistribution history has uncertainties that vary in

463 space and time, partly because some sites have more erosion and deposition rate measurements

464 than others, and partly because empirical constraints on erosion and deposition rates are rarer

465 deeper in the past. Modeled erosion rates have uncertainties up to a factor of 2 related to the

466 time-space relationship used in the stream profile inversions (Fox et al., 2014). Additionally, we

467 are unaware of deposition rate measurements that predate the Holocene on the west coast and of

468 any age on the east coast. For areas lacking deposition rate measurements, the applied

469 deposition rates and patterns depend on the deposition model parameters (cone and shelf angle).

470 Thus, for some regions and time periods, empirical data are unable to provide strong constraints

471 on past variations of sediment redistribution.

472 However, other aspects of the sediment redistribution history are relatively well

473 constrained. The highest erosion rates in the predicted sediment redistribution history $(\sim 12$

$474 \mathrm{~mm} / \mathrm{yr}$ ) are consistent with previously published estimates of highest channel incision rates

475 (Dadson et al., 2003) of 9 to $>15 \mathrm{~mm} / \mathrm{yr}$. Similarly, the fastest deposition rates in our sediment

476 redistribution history (152 mm/yr distributed over a 400-km² region, mass load $66 \mathrm{Mt} / \mathrm{yr})$ are

477 broadly consistent with fluvial sediment fluxes as high as $88 \mathrm{Mt} / \mathrm{yr}$ out of the east coast rivers

478 feeding these deposits (Dadson et al., 2003). The total island-wide eroded sediment discharge

$479192 \mathrm{Mt} / \mathrm{yr}$ is only $\sim 7 \%$ higher than the 20-year average sediment discharge reported by Kao and

480 Milliman (2008) of $180 \mathrm{Mt} / \mathrm{yr}$ transported by the 16 largest rivers. Given that sea-level responses

481 are approximately linearly related to the cumulative sediment flux for a given sediment 
482 redistribution geometry (Ferrier et al., 2015, 2017), this suggests that uncertainties associated 483 with the total sediment flux may be relatively small in these simulations. Modeled sea-level changes are also sensitive to the choice of Earth model. For example,

485 Figures 5 and 6 reveal significant differences in sea-level responses between the SL30 and SL10 486 simulations, which differ only in the effective elastic thickness of the lithosphere (30 km and 10 $487 \mathrm{~km}$, respectively). In the SL10 simulations, marine deposition induces crustal subsidence with a 488 larger amplitude and shorter wavelength than in the SL30 simulations, because crustal responses 489 are flexurally filtered more strongly by the more rigid lithosphere in the SL30 simulations. These 490 effects are especially apparent on the island of Lanyu, where $R S L_{G R}$ at $8 \mathrm{ka}$ is as much as 8 491 meters higher in SL30 simulations than in SL10 simulations (Figure 6). As a result, $\Delta S L_{G R}$ in 492 Lanyu and Lutao increases in the SL10 simulations and decreases in the SL30 simulations, 493 highlighting the sensitivity of modeled sea-level responses to $T_{e}$. As stated in Section 5.2, we 494 consider estimates of rock uplift to be lower bounds for those sites based on sea-level markers 495 without reported lower bounds on the depth of formation.

496 Lastly, we note that sea-level responses in our simulations are governed by a spherically 497 symmetric Earth model, a characteristic shared by nearly all implementations of the sea-level 498 theory due to the computational expense of computing sea-level responses with a laterally 499 varying 3-D Earth model (e.g., Latychev et al., 2005; de Boer et al., 2017; Gomez et al., 2018;

500 Crawford et al., 2018). This approach necessarily neglects several things that may affect sea501 level changes in Taiwan, including lateral variations in mantle and lithospheric properties 502 (viscosity, elasticity, density, thickness), brittle crustal deformation, and crustal underplating, and 503 other tectonic processes (e.g., Suppe, 1984). Like all other spherically symmetric 504 implementations of the sea-level model, our simulations cannot account for these processes, so 
505 we emphasize that our modeled sea-level responses isolate the sea-level change driven by

506 sediment redistribution, which is a portion of the total sea-level change. Nonetheless, our

507 simulations illustrate the sensitivity of sea-level responses to Earth model characteristics, and

508 they motivate ongoing efforts to constrain regional variations in these characteristics. and to

509 develop methodologies that can account for them.

511 6. Conclusions

The central contribution of this study is new simulations showing that the combination of

514 rapid onshore erosion and rapid offshore deposition is capable of generating rapid sea-level fall

515 along Taiwan's east coast. Our simulations imply that sediment redistribution is large enough to

516 have driven sea-level fall along Taiwan's eastern shore of $>10 \mathrm{~m}$ over the past $10 \mathrm{ka}$ and $>100 \mathrm{~m}$

517 since the last interglacial at $\sim 120 \mathrm{ka}$. Contrary to the behavior observed in many other coastal

518 areas with massive sediment fluxes (e.g., large deltas), sediment redistribution around Taiwan

519 tends to drive sea-level fall, rather than sea-level rise.

520 The sediment-driven sea-level fall can help resolve elevation differences between

521 observed paleo-sea-level markers in Taiwan and modeled sea-level changes, and our simulations

522 imply that sediment redistribution may have affected SL marker elevations on islands as far

523 away as $\sim 100 \mathrm{~km}$ from Taiwan. This suggests that a significant portion of recent crustal uplift

524 along Taiwan's east coast may be caused in part by erosional unloading, which in turn suggests

525 that estimates of tectonically driven rock uplift rates inferred from paleo-sea-level markers may

526 need to be revised downward by as much as $2 \mathrm{~mm} / \mathrm{yr}$ in this region. These results highlight the 
527 importance of accounting for sediment redistribution — particularly rapid erosion—in

528 interpretations of past sea-level change in tectonically active regions.

530 Acknowledgments

GAR and KLF were supported by NASA award 16-IDS16-0093, and KLF was supported

533 by ACS-PRF award 58209-DNI8 and NSF award EAR-1525922. MF was supported by NERC

534 award NE/N015479/1. We thank Jacqueline Austermann for providing sea level code, Robert

535 Moucha for helpful discussion, and two anonymous reviewers whose comments greatly

536 improved the manuscript.

539 References

540

541 Austermann, J., Mitrovica, J. X., Latychev, K., \& Milne, G. A. (2013). Barbados-based estimate

542 of ice volume at Last Glacial Maximum affected by subducted plate. Nature

$543 \quad$ Geoscience, 6(7), 553.

544 Austermann, J. and Mitrovica, J.X., 2015. Calculating gravitationally self-consistent sea level

545 changes driven by dynamic topography. Geophysical Journal International, 203(3), pp.1909-

5461922.

547 Austermann, J., Mitrovica, J.X., Huybers, P. and Rovere, A., 2017. Detection of a dynamic 548 topography signal in last interglacial sea-level records. Science Advances, 3(7), p.e1700457. 
Becker, J. J., D. T. Sandwell, W. H. F. Smith, J. Braud, B. Binder, J. Depner, D. Fabre, J. Factor,

550 S. Ingalls, S-H. Kim, R. Ladner, K. Marks, S. Nelson, A. Pharaoh, R. Trimmer, J. Von

551 Rosenberg, G. Wallace, P. Weatherall., Global Bathymetry and Elevation Data at 30 Arc

552 Seconds Resolution: SRTM30_PLUS, Marine Geodesy, 32:4, 355-371, 2009.

553 Chen, B., Chen, C., Kaban, M.K., Du, J., Liang, Q. and Thomas, M., 2013. Variations of the

554 effective elastic thickness over China and surroundings and their relation to the lithosphere 555 dynamics. Earth and Planetary Science Letters, 363, pp.61-72.

556 Chen C., 2003. Accelerating seismicity of moderate-size earthquakes before the 1999 Chi-Chi,

557 Taiwan, earthquake: Testing time-prediction of the self-organizing spinodal model of

558 earthquakes, Geophysical Journal International, Volume 155, Issue 1, Pages F1-F5,

$559 \quad$ https://doi.org/10.1046/j.1365-246X.2003.02071.x

560 Chen, Y.W., Shyu, J.B.H. and Chang, C.P., 2015. Neotectonic characteristics along the eastern

561 flank of the Central Range in the active Taiwan orogen inferred from fluvial channel

562 morphology. Tectonics, 34(10), pp.2249-2270.

563 Crawford, O., Al-Attar, D., Tromp, J., Mitrovica, J. X., Austermann, J., \& Lau, H. C. (2018).

564 Quantifying the sensitivity of post-glacial sea level change to laterally varying

565 viscosity. Geophysical journal international, 214(2), 1324-1363.

566 Creveling, J.R., Mitrovica, J.X., Hay, C.C., Austermann, J. and Kopp, R.E., 2015. Revisiting

567 tectonic corrections applied to Pleistocene sea-level highstands. Quaternary Science Reviews, $568 \quad 111, \mathrm{pp} .72-80$.

569 Creveling, J. R., Mitrovica, J. X., Clark, P. U., Waelbroeck, C., \& Pico, T. (2017). Predicted

570 bounds on peak global mean sea level during marine isotope stages 5a and 5c. Quaternary

$571 \quad$ Science Reviews, 163, 193-208. 
572 Dadson, S.J., Hovius, N., Chen, H., Dade, W.B., Hsieh, M.L., Willett, S.D., Hu, J.C., Horng,

573 M.J., Chen, M.C., Stark, C.P. and Lague, D., 2003. Links between erosion, runoff variability

$574 \quad$ and seismicity in the Taiwan orogen. Nature, 426(6967), p.648.

575 Dalca, A.V., Ferrier, K.L., Mitrovica, J.X., Perron, J.T., Milne, G.A. and Creveling, J.R., 2013.

576 On postglacial sea level-III. Incorporating sediment redistribution. Geophysical Journal

577 International, 194(1), pp.45-60.

578 de Boer, B., Stocchi, P., Whitehouse, P.L. and van de Wal, R.S., 2017. Current state and future

579 perspectives on coupled ice-sheet-sea-level modelling. Quaternary Science Reviews, 169,

$580 \quad$ pp.13-28.

581 Doar, W.R. and Kendall, C.G.S.C., 2014. An analysis and comparison of observed Pleistocene

582 South Carolina (USA) shoreline elevations with predicted elevations derived from Marine

583 Oxygen Isotope Stages. Quaternary Research, 82(1), pp.164-174.

584 Dutton, A., \& Lambeck, K. (2012). Ice volume and sea level during the last interglacial.

$585 \quad$ Science, 337(6091), 216-219.

586 Dziewonski, A.M. and Anderson, D.L., 1981. Preliminary reference Earth model. Physics of the 587 earth and planetary interiors, 25(4), pp.297-356.

588 Farrell, W. E., \& Clark, J. A. (1976). On postglacial sea level. Geophysical Journal of the Royal $589 \quad$ Astronomical Society, 46(3), 647-667.

590 Ferrier, K.L., Mitrovica, J.X., Giosan, L. and Clift, P.D., 2015. Sea-level responses to erosion 591 and deposition of sediment in the Indus River basin and the Arabian Sea. Earth and

592 Planetary Science Letters, 416, pp.12-20. 
593 Ferrier, K.L., Austermann, J., Mitrovica, J.X. and Pico, T., 2017. Incorporating sediment

594 compaction into a gravitationally self-consistent model for ice age sea-level change.

595 Geophysical Journal International, 211(1), pp.663-672.

596 Ferrier, K. L., Li, Q., Pico, T., \& Austermann, J. (2018). The Influence of Water Storage in 597 Marine Sediment on Sea-Level Change. Geophysical Research Letters, 45(5), 2444-2454.

598 Fox, M., Goren, L., May, D.A. and Willett, S.D., 2014. Inversion of fluvial channels for 599 paleorock uplift rates in Taiwan. Journal of Geophysical Research: Earth Surface, 119(9), $600 \quad$ pp.1853-1875.

601 Gomez, N., Latychev, K. and Pollard, D., 2018. A Coupled Ice Sheet-Sea Level Model

602 Incorporating 3D Earth Structure: Variations in Antarctica during the Last Deglacial Retreat.

603 Journal of Climate, 31(10), pp.4041-4054.

604 Haskell, N. A. (1935). The motion of a viscous fluid under a surface load. Physics, 6(8), 265605269.

606 Hsu, W.H., Byrne, T.B., Ouimet, W., Lee, Y.H., Chen, Y.G., Soest, M.V. and Hodges, K., 2016.

607 Pleistocene onset of rapid, punctuated exhumation in the eastern Central Range of the

608 Taiwan orogenic belt. Geology, 44(9), pp.719-722.

609 Hsu, Y.J., Lai, Y.R., You, R.J., Chen, H.Y., Teng, L.S., Tsai, Y.C., Tang, C.H. and Su, H.H., 610 2018. Detecting rock uplift across southern Taiwan mountain belt by integrated GPS and 611 leveling data. Tectonophysics, 744, pp.275-284.

612 Hsieh, M.L., Liew, P.M. and Hsu, M.Y., 2004. Holocene tectonic uplift on the Hua-tung coast,

613 eastern Taiwan. Quaternary International, 115, pp.47-70.

614 Huang, M.H., Hu, J.C., Ching, K.E., Rau, R.J., Hsieh, C.S., Pathier, E., Fruneau, B. and 615 Deffontaines, B., 2009. Active deformation of Tainan tableland of southwestern Taiwan 

based on geodetic measurements and SAR interferometry. Tectonophysics, 466(3-4), pp.322334.

618 Karpytchev, M., Ballu, V., Krien, Y., Becker, M., Goodbred, S., Spada, G., ... \& Khan, Z.

619 (2018). Contributions of a Strengthened Early Holocene Monsoon and Sediment Loading to 620 Present-Day Subsidence of the Ganges-Brahmaputra Delta. Geophysical Research $621 \quad$ Letters, 45(3), 1433-1442.

622 Kendall, R.A., Mitrovica, J.X. and Milne, G.A., 2005. On post-glacial sea level-II. Numerical 623 formulation and comparative results on spherically symmetric models. Geophysical Journal International, 161(3), pp.679-706.

625 Kopp, R. E., Simons, F. J., Mitrovica, J. X., Maloof, A. C., \& Oppenheimer, M. (2009).

626 Probabilistic assessment of sea level during the last interglacial stage. Nature, 462(7275), 863.

Kuchar, J., Milne, G., Wolstencroft, M., Love, R., Tarasov, L., \& Hijma, M. (2018). The influence of sediment isostatic adjustment on sea level change and land motion along the US Gulf Coast. Journal of Geophysical Research: Solid Earth, 123(1), 780-796.

632 definition in the glacio-hydro-isostatic sea-level equation. Quaternary Science Reviews, $633 \quad 22(2-4)$, pp.309-318.

634 Latychev, K., Mitrovica, J. X., Tromp, J., Tamisiea, M. E., Komatitsch, D., \& Christara, C. C.

635 (2005). Glacial isostatic adjustment on 3-D Earth models: a finite-volume

636 formulation. Geophysical Journal International, 161(2), 421-444.

637 Lee, J.C., Chu, H.T., Angelier, J., Chan, Y.C., Hu, J.C., Lu, C.Y. and Rau, R.J., 2002. Geometry 638 and structure of northern surface ruptures of the $1999 \mathrm{Mw}=7.6 \mathrm{Chi}$-Chi Taiwan earthquake: 
influence from inherited fold belt structures. Journal of Structural Geology, 24(1), pp.173192.

641 Lin, A.T. and Watts, A.B., 2002. Origin of the West Taiwan basin by orogenic loading and 642 flexure of a rifted continental margin. Journal of Geophysical Research: Solid Earth, 107(B9), pp.ETG-2.

644 Liu, T.K., Hsieh, S., Chen, Y.G. and Chen, W.S., 2001. Thermo-kinematic evolution of the 645 Taiwan oblique-collision mountain belt as revealed by zircon fission track dating. Earth and 646 Planetary Science Letters, 186(1), pp.45-56.

647 Liu, J.P., Liu, C.S., Xu, K.H., Milliman, J.D., Chiu, J.K., Kao, S.J. and Lin, S.W., 2008. Flux and 648 fate of small mountainous rivers derived sediments into the Taiwan Strait. Marine Geology, $649 \quad 256(1-4)$, pp.65-76.

650 Lisiecki, L.E. and Raymo, M.E., 2005. A Pliocene-Pleistocene stack of 57 globally distributed 651 benthic $\delta 180$ records. Paleoceanography, 20(1).

652 McGinnis, J.P., Driscoll, N.W., Karner, G.D., Brumbaugh, W.D. and Cameron, N., 1993.

653 Flexural response of passive margins to deep-sea erosion and slope retreat: implications for 654 relative sea-level change. Geology, 21(10), pp.893-896.

655 Merritts, D., \& Bull, W. B. (1989). Interpreting Quaternary uplift rates at the Mendocino triple 656 junction, northern California, from uplifted marine terraces. Geology, 17(11), 1020-1024.

657 Milliman, J. D., \& Farnsworth, K. L. (2013). River discharge to the coastal ocean: a global 658 synthesis. Cambridge University Press.

659 Milne, G.A., Davis, J.L., Mitrovica, J.X., Scherneck, H.G., Johansson, J.M., Vermeer, M. and 660 Koivula, H., 2001. Space-geodetic constraints on glacial isostatic adjustment in 661 Fennoscandia. Science, 291(5512), pp.2381-2385. 
Mitrovica, J.X., Tamisiea, M.E., Davis, J.L. and Milne, G.A., 2001. Recent mass balance of

663 polar ice sheets inferred from patterns of global sea-level change. Nature, 409(6823), p.1026.

664 Moucha, R., Forte, A.M., Mitrovica, J.X., Rowley, D.B., Quéré, S., Simmons, N.A. and Grand,

665 S.P., 2008. Dynamic topography and long-term sea-level variations: There is no such thing as

666 a stable continental platform. Earth and Planetary Science Letters, 271(1-4), pp.101-108.

667 Moucha, R. and Ruetenik, G.A., 2017. Interplay between dynamic topography and flexure along

668 the US Atlantic passive margin: Insights from landscape evolution modeling. Global and

669 Planetary Change, 149, pp.72-78.

670 Ruetenik, G., Moucha, R. and de Boer, B., 2019. Deformation in response to landscape evolution

671 during glacial cycles on the US Atlantic passive margin. Earth and Planetary Science

$672 \quad$ Letters, 526, p.115759.

673 Muhs, D.R., Kelsey, H.M., Miller, G.H., Kennedy, G.L., Whelan, J.F. and McInelly, G.W.,

674 1990. Age estimates and uplift rates for late Pleistocene marine terraces: Southern Oregon

675 portion of the Cascadia forearc. Journal of Geophysical Research: Solid Earth, 95(B5),

$676 \quad$ pp.6685-6698.

677 Nicholls, R.J. and Cazenave, A., 2010. Sea-level rise and its impact on coastal zones. Science,

$678 \quad 328(5985)$, pp.1517-1520.

679 Omura, A. and Ota, Y., 1992. Paleo sea-level change during the last 300, 000 years deduced

680 from the morpho-stratigraphy of coral reef terraces and $230 \mathrm{Th} / 234 \mathrm{U}$ ages of terrace deposits.

681 The Quaternary Research (Daiyonki-Kenkyu), 31(5), pp.313-327.

682 Peltier, W.R., 2004. Global glacial isostasy and the surface of the ice-age Earth: the ICE-5G

683 (VM2) model and GRACE. Annu. Rev. Earth Planet. Sci., 32, pp.111-149. 
684 Pico, T., Mitrovica, J. X., Ferrier, K. L., \& Braun, J. (2016). Global ice volume during MIS 3

685 inferred from a sea-level analysis of sedimentary core records in the Yellow River

686 Delta. Quaternary Science Reviews, 152, 72-79.

687 Pico, T., Creveling, J.R. and Mitrovica, J.X., 2017. Sea-level records from the US mid-Atlantic

688 constrain Laurentide Ice Sheet extent during Marine Isotope Stage 3. Nature

689 communications, $8(1)$, pp.1-6.

690 Portenga, E.W. and Bierman, P.R., 2011. Understanding Earth's eroding surface with 10 Be.

691 GSA today, 21(8), pp.4-10.

692 Raymo, M. E., Mitrovica, J. X., O’Leary, M. J., DeConto, R. M., \& Hearty, P. J. (2011).

693 Departures from eustasy in Pliocene sea-level records. Nature Geoscience, 4(5), 328.

694 Reynolds, D.J., Steckler, M.S. and Coakley, B.J., 1991. The role of the sediment load in

695 sequence stratigraphy: the influence of flexural isostasy and compaction. Journal of

696 Geophysical Research: Solid Earth, 96(B4), pp.6931-6949.

697 Rovere, A., Raymo, M.E., Mitrovica, J.X., Hearty, P.J., O’Leary, M.J. and Inglis, J.D., 2014.

698 The Mid-Pliocene sea-level conundrum: Glacial isostasy, eustasy and dynamic topography.

699 Earth and Planetary Science Letters, 387, pp.27-33.

700 Rowley, D. B., Forte, A. M., Moucha, R., Mitrovica, J. X., Simmons, N. A., \& Grand, S. P.

701 (2013). Dynamic topography change of the eastern United States since 3 million years

702 ago. Science, 340(6140), 1560-1563.

703 Ruetenik, G.A., Moucha, R. and Hoke, G.D., 2016. Landscape response to changes in dynamic

$704 \quad$ topography. Terra Nova, 28(4), pp.289-296.

705 
Simms, A.R., Anderson, J.B., DeWitt, R., Lambeck, K. and Purcell, A., 2013. Quantifying rates

707 of coastal subsidence since the last interglacial and the role of sediment loading. Global and

708 Planetary Change, 111, pp.296-308.

709 Simms, A.R., Rouby, H. and Lambeck, K., 2016. Marine terraces and rates of vertical tectonic

710 motion: The importance of glacio-isostatic adjustment along the Pacific coast of central

$711 \quad$ North America. Bulletin, 128(1-2), pp.81-93.

712 Suppe, J., 1981. Mechanics of mountain building and metamorphism in Taiwan. Mem. Geol.

713 Soc. China, 4(6), pp.67-89.

714 Suppe, J., 1984. Kinematics of arc-continent collision, flipping of subduction, and back-arc

715 spreading near Taiwan. Memoir. Geol. Soc. China, 6, pp.21-33.

716 Szwillus, W., Ebbing, J. and Holzrichter, N., 2016. Importance of far-field topographic and

717 isostatic corrections for regional density modelling. Geophysical Journal International, $718 \quad 207(1)$, pp.274-287.

719 Tamisiea, M.E., Mitrovica, J.X., Milne, G.A. and Davis, J.L., 2001. Global geoid and sea level

720 changes due to present-day ice mass fluctuations. Journal of Geophysical Research: Solid

$721 \quad$ Earth, 106(B12), pp.30849-30863.

722 Teng, L.S., Lee, C.T., Tsai, Y.B. and Hsiao, L.Y., 2000. Slab breakoff as a mechanism for

723 flipping of subduction polarity in Taiwan. Geology, 28(2), pp.155-158.

724 Tesauro, M., Kaban, M.K. and Cloetingh, S.A., 2012. Global strength and elastic thickness of the 725 lithosphere. Global and Planetary Change, 90, pp.51-57.

726 Vita-Finzi, C., 2000. Deformation and seismicity of Taiwan. Proceedings of the National 727 Academy of Sciences, 97(21), pp.11176-11180.

728 Vita-Finzi, C. and Lin, J.C., 1998. Serial reverse and strike slip on imbricate faults: The Coastal 
730 Wang, C.H. and Burnett, W.C., 1990. Holocene mean uplift rates across an active plate-collision

731 boundary in Taiwan. Science, 248(4952), pp.204-206.

732 Willett, S.D., Fisher, D., Fuller, C., En-Chao, Y. and Chia-Yu, L., 2003. Erosion rates and

733 orogenic-wedge kinematics in Taiwan inferred from fission-track thermochronometry.

734 Geology, 31(11), pp.945-948.

735 Wu, F.T., 1978. Recent tectonics of Taiwan. Journal of Physics of the Earth, 26(Supplement), $736 \quad$ pp.S265-S299.

737 Wolstencroft, M., Shen, Z., Törnqvist, T.E., Milne, G.A. and Kulp, M., 2014. Understanding 738 subsidence in the Mississippi Delta region due to sediment, ice, and ocean loading: Insights 739 from geophysical modeling. Journal of Geophysical Research: Solid Earth, 119(4), pp.3838$740 \quad 3856$.

741 Woo, H. B., Panning, M. P., Adams, P. N., \& Dutton, A. (2017). Karst-driven flexural isostasy in 742 North-Central Florida. Geochemistry, Geophysics, Geosystems, 18(9), 3327-3339.

743 Yu, S.B., Chen, H.Y. and Kuo, L.C., 1997. Velocity field of GPS stations in the Taiwan area. 744 Tectonophysics, 274(1-3), pp.41-59. 

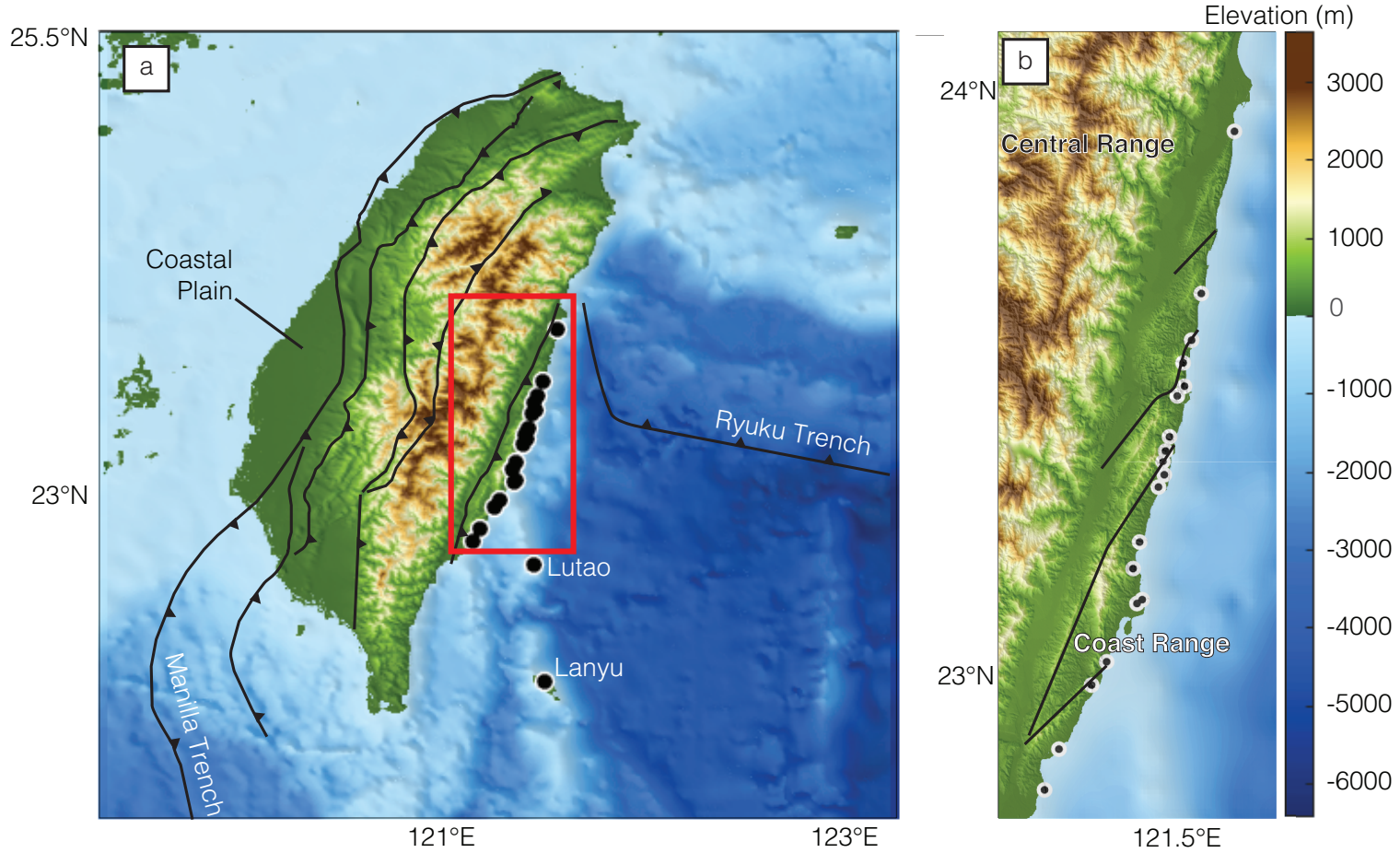

753

754

755

756

757

758

759

760

761

762
Figure 1: a) Locations of SL markers in eastern Taiwan (black circles; Table S1) and major faults after Lee et al., (2002). b) Zoomed in image of the coast range showing faults (black lines) from Vita Finzi and Lin (1998). 


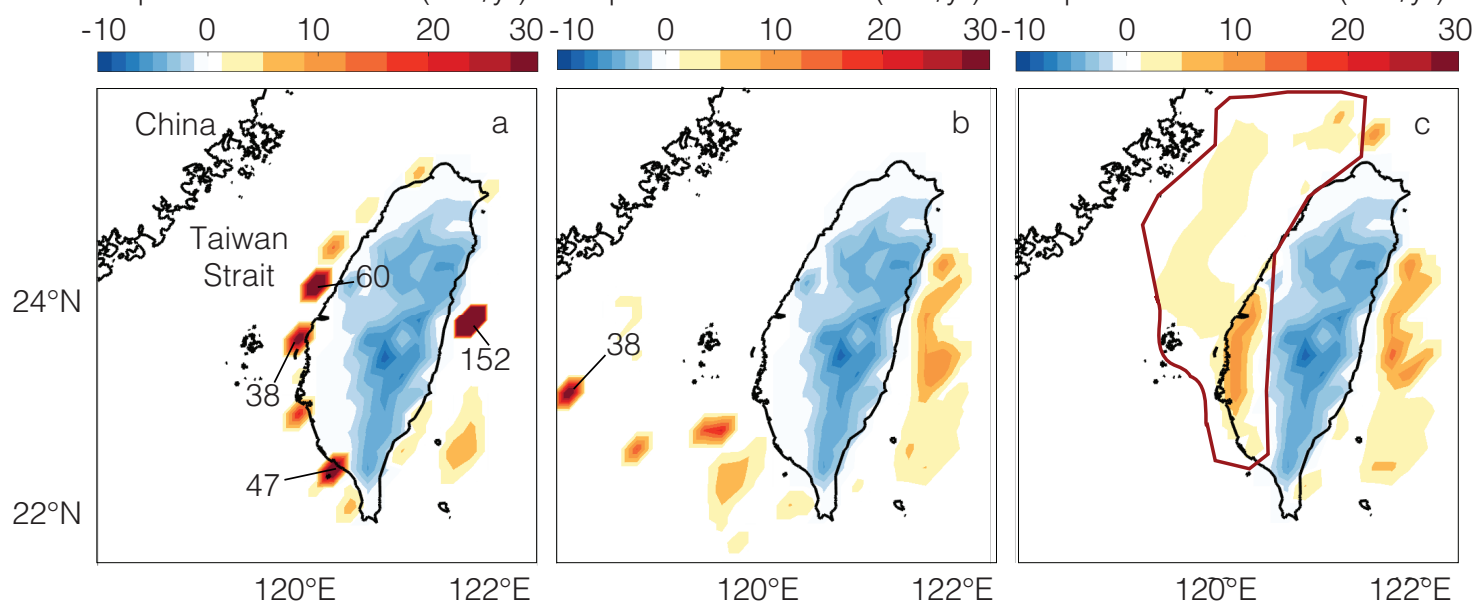

Figure 2: Snapshots of erosion rates (blue, negative values) and deposition rates (yellow to red, positive values) in Taiwan at $120 \mathrm{ka}$ (panel a), $20 \mathrm{ka} \mathrm{(b),} \mathrm{and} 0.1 \mathrm{ka} \mathrm{(c),} \mathrm{which} \mathrm{are} \mathrm{representative}$ of the rates used to reconstruct the history of sediment redistribution over the last glacial cycle. Rates were taken from erosion rate reconstructions in Fox et al. (2014), deposition rate measurements in Liu et al. (2008), and application of the marine deposition model of Ruetenik et al. (2016). The sediment redistribution history generated from these rates was used to drive sealevel responses (Section 3.2). Labeled numbers represent deposition rates ( $\mathrm{mm} / \mathrm{yr}$ ) for saturated values. The purple line in panel c shows the area over which the Liu et al. (2008) data were applied. 

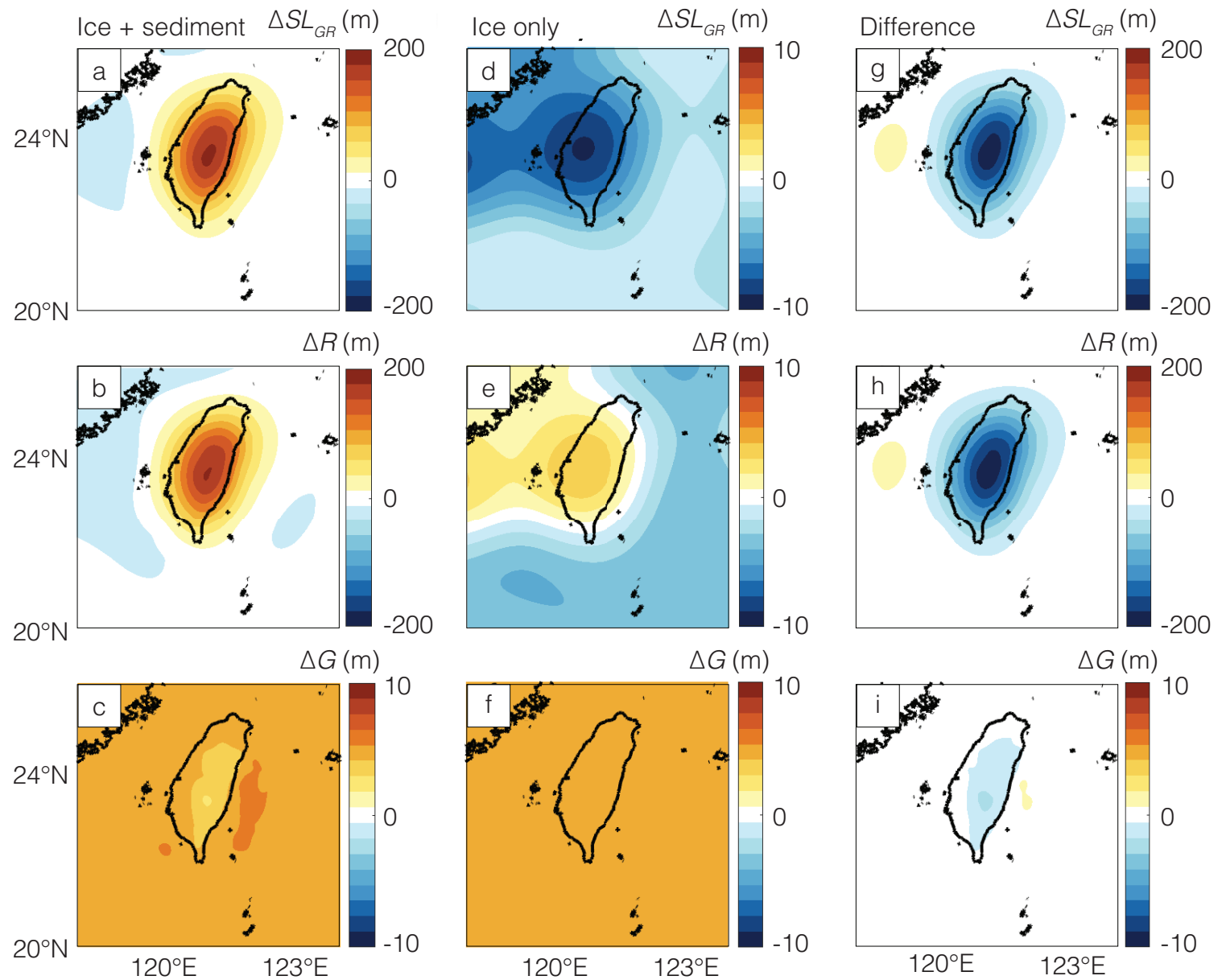

779 Figure 3a-c: Cumulative changes in sea level $\left(\Delta S L_{G R}=\Delta G-\Delta R\right.$; panel a), crustal elevation

780 ( $\Delta R$; panel b), and the sea-surface equipotential $(\Delta G$; panel $\mathrm{c})$ at the end of a 122-kyr simulation

781 driven by regional sediment redistribution (Figure 2) and global ice mass changes. d-f. As in panels a-c, except for a simulation driven only by global ice mass changes. g. The difference between panels $\mathrm{d}$ and a isolates the net contribution of sediment redistribution to $\triangle S L_{G R}$, and shows that these effects form a bullseye pattern around Taiwan. $\mathbf{h}$-i. As in panel g, except for sediment's contribution to the differences in $\Delta R$ and $\Delta G$, respectively. These show that sediment redistribution has a much larger effect on the change in sea level over this time period in Taiwan (panel g) than global ice volume changes do (panel d). Note differences in color bar scales between frames. 

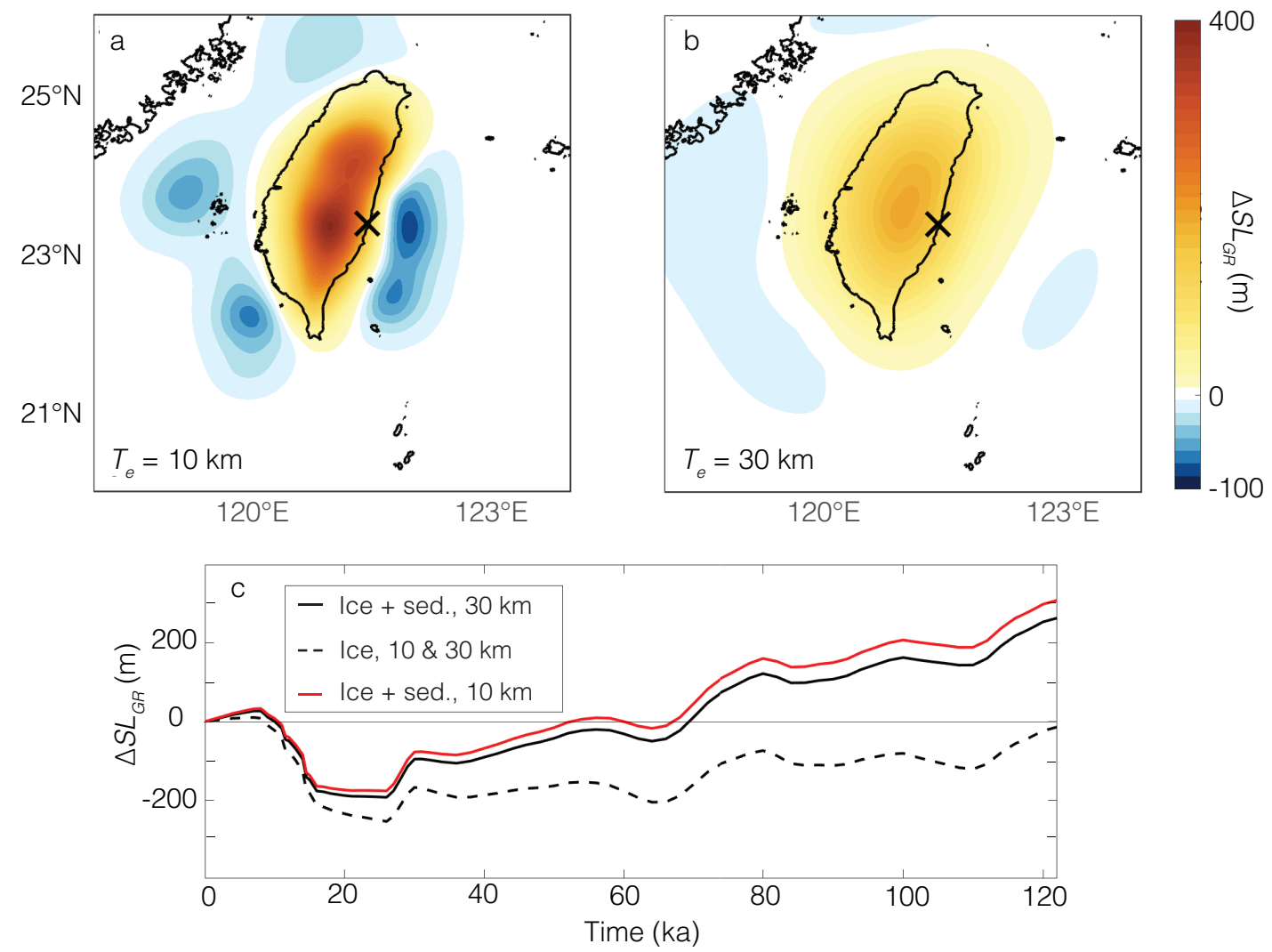

Figure 4: Sensitivity of modeled sea-level change to lithospheric effective elastic thickness. a. The difference in modeled sea-level change $\left(\Delta S L_{G R}=\Delta G-\Delta R\right)$ at the end of two 122-kyr simulations, one driven by regional sediment redistribution and global ice variations, and the other driven only by ice (as in Figure $3 g$ ), for an Earth model with a lithospheric effective elastic thickness $T_{e}$ of $10 \mathrm{~km}$. b. As in panel a, except for an Earth model with $T_{e}=30 \mathrm{~km}$. A comparison of panels a and $\mathrm{b}$ shows that sea-level responses are narrower in space and higher in amplitude at smaller $T_{e}$. c. Histories of modeled sea-level change at the point on Taiwan's east coast marked with a black $X$ in panels $a-b$ for four simulations. Two are driven by sediment redistribution and global ice changes on Earth models with $T_{e}=10 \mathrm{~km}$ (black line) and $T_{e}=30$ $\mathrm{km}$ (red line). The remaining two are driven only by global ice changes with $T_{e}=10 \mathrm{~km}$ and 30 $\mathrm{km}$, and overlap with each other within the width of the dashed line in panel c. The difference between the dashed line and solid lines shows that sediment redistribution can perturb LIG-age paleoshorelines by $>100 \mathrm{~m}$ in eastern Taiwan, implying that paleoshoreline-based inferences of paleo-sea-level change may be strongly affected by sediment redistribution here. 


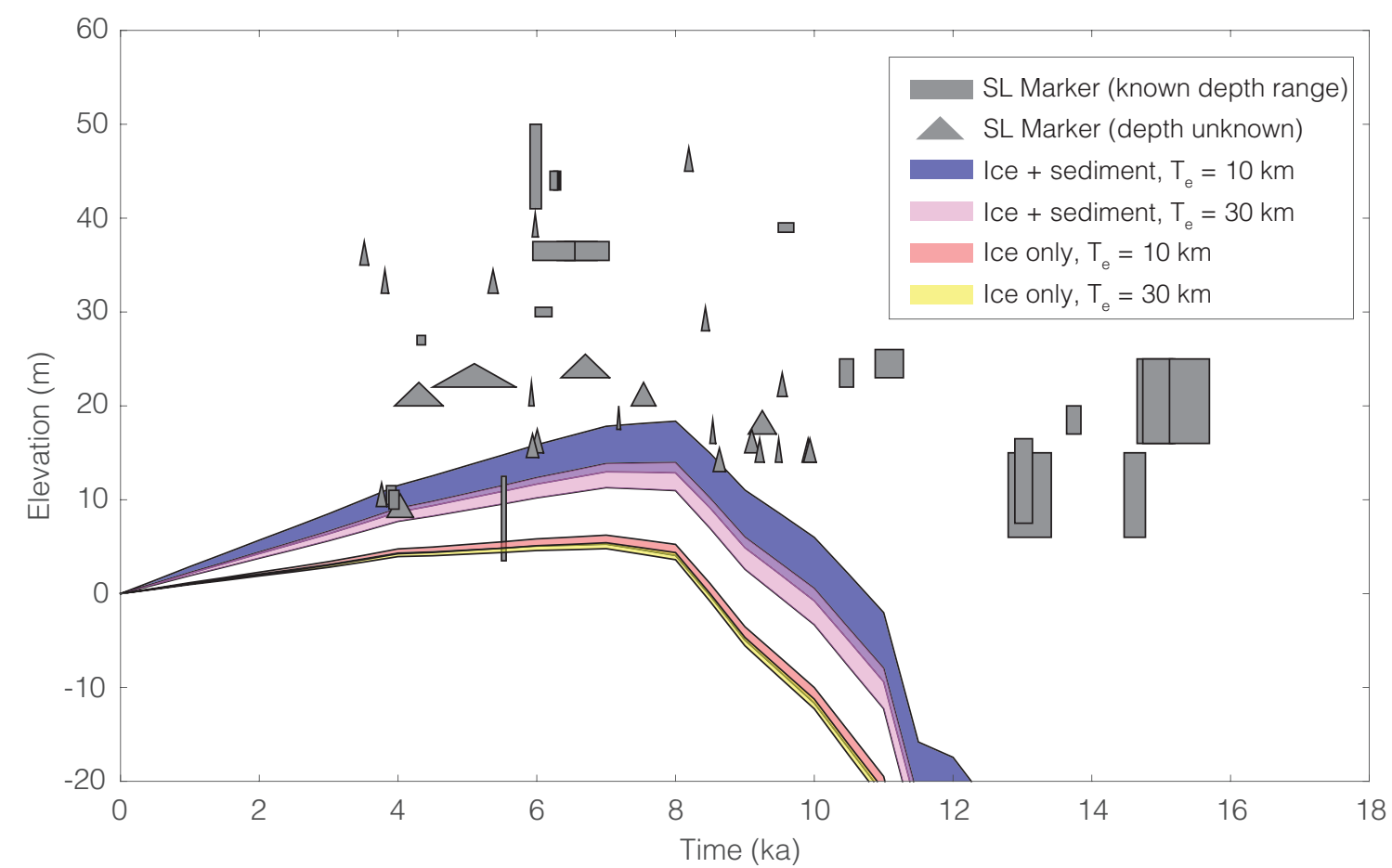

Figure 5: Observed and modeled sea-level histories on the east coast of Taiwan. Gray boxes show observed paleo-sea-level marker ages and elevations (Hsieh et al., 2004). Box widths and heights show the ranges in paleo-sea-level marker age and elevation over all localities on the east coast of Taiwan (Figure 1). Triangles represent minimum elevations where the deposited depth range is undefined, and triangle widths correspond to age ranges. Colored regions show the range in modeled relative sea level $(R S L)$ among all localities along Taiwan's east coast in four simulations. Two simulations were driven by the ice and sediment variations in Section 3 (pink and purple for Earth models with $T_{e}=10 \mathrm{~km}$ and $30 \mathrm{~km}$, respectively), and two simulations were driven by ice variations only (orange and yellow for $T_{e}=10 \mathrm{~km}$ and $30 \mathrm{~km}$, respectively). This shows that accounting for sediment redistribution increases modeled $R S L$ substantially, which brings the modeled sea-level history closer to - but generally still lower than - most of the observed paleo-sea-level markers. 

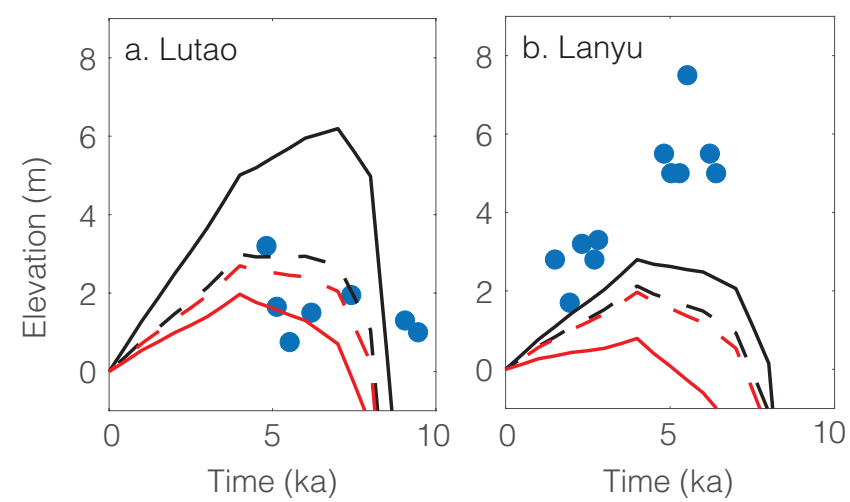

838 Figure 6: Comparison of observed and modeled relative sea-level histories on the islands of Lutao (panel a) and Lanyu (panel b), which lie $\sim 30 \mathrm{~km}$ and $\sim 65 \mathrm{~km}$ east of Taiwan, respectively

840 (Figure 1). Blue dots show elevations and ages of paleo-sea-level markers. Lines show modeled

$841 R S L$ histories in simulations driven by sediment and ice variations (solid lines) and only ice

842 variations (dashed lines) for Earth models with $T_{e}=30 \mathrm{~km}$ (black) and $T_{e}=10 \mathrm{~km}$ (red). These

843 show that sediment redistribution in Taiwan is capable of significantly affecting sea-level

844 changes at sites $>60 \mathrm{~km}$ away from Taiwan. The difference between the SL10 and SL30

845 simulations illustrate the effects of lithospheric thickness on modeled $R S L$ and hence elevation

846 differences between observed paleoshorelines and modeled RSL. 

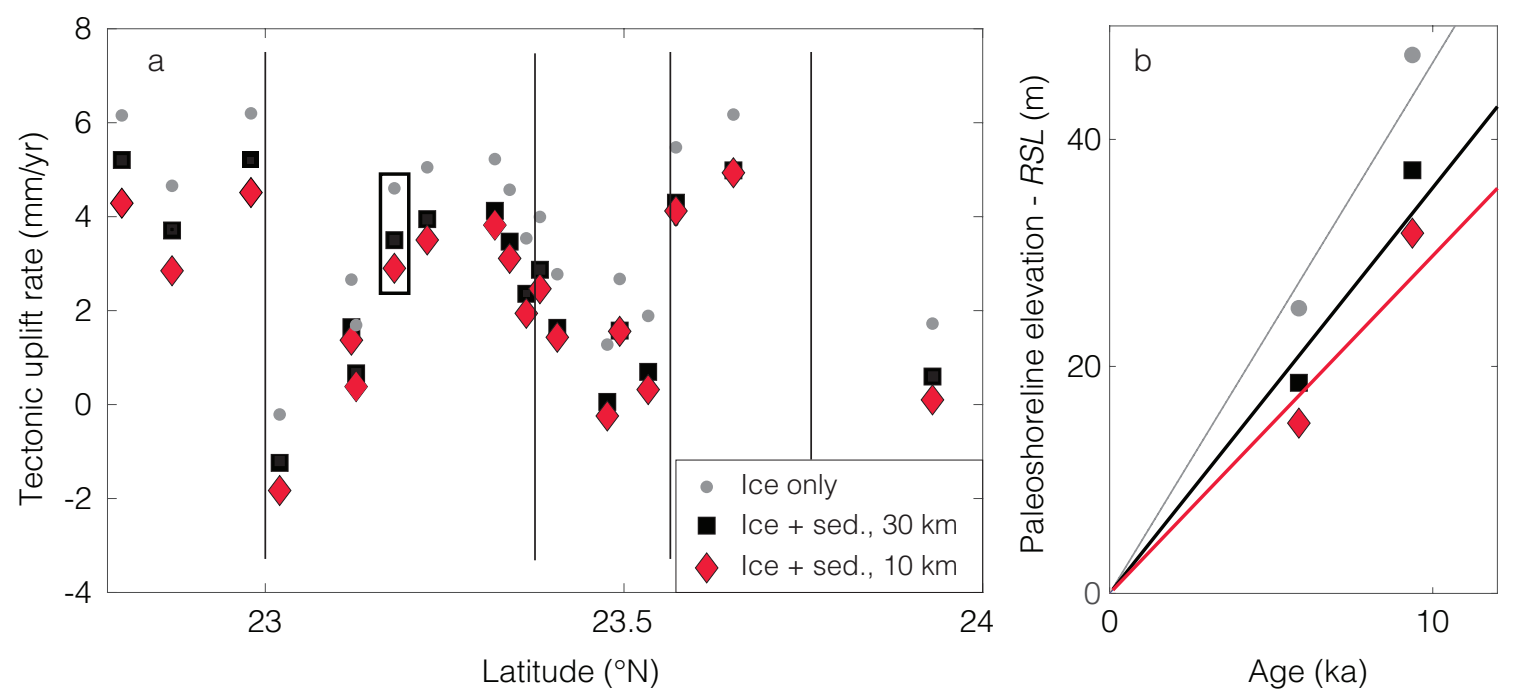

Figure 7a: Estimates of tectonically driven rock uplift rates, $U_{\text {tectonic, }}$ along Taiwan's east coast. These are inferred from residuals between observed paleoshoreline elevations and modeled sealevel changes (Figure 5). Vertical lines indicate locations of inferred fault (Vita-Finzi and Lin, 1998). Inferred tectonically driven uplift rates are systematically smaller in simulations driven by both sediment and ice, indicating that estimates of tectonically driven uplift rates on Taiwan's east coast would be overestimated if sediment redistribution were not accounted for. $\mathbf{b}$. An example of how the uplift rates in panel a were calculated. All rates were determined from the slope of a linear regression between paleo-sea-level marker age and the difference between the paleo-sea-level elevation and modeled $R S L$. Here, the data correspond to the rates in panel a at $23.18^{\circ} \mathrm{N}$. Gray circles represent ages and residual elevations inferred from sea-level simulations driven only by global ice variations. Red diamonds and black squares represent ages and residual elevations inferred from simulations driven by both sediment and ice variations in Earth models with 10-km and 30-km effective elastic lithospheric thicknesses, respectively. 
868

869 